OPEN ACCESS

Edited by:

Eugene A. Goodilin, Lomonosov Moscow State

University, Russia

Reviewed by:

Andrei Baranov,

Lomonosov Moscow State

University, Russia

Vitaly V. Kuznetsov,

D. Mendeleyev University of Chemical

Technology of Russia, Russia

*Correspondence:

Oleg I. Silyukov

oleg.silyukov@spbu.ru

Specialty section

This article was submitted to Catalysis and Photocatalysis,

a section of the journal

Frontiers in Chemistry

Received: 16 February 2020

Accepted: 26 March 2020

Published: 23 April 2020

Citation:

Voytovich W, Kurnosenko SA,

Silyukov OI, Rodionov IA, Minich IA and Zvereva IA (2020) Study of n-alkylamine Intercalated Layered

Perovskite-Like Niobates

$\mathrm{HCa}_{2} \mathrm{Nb}_{3} \mathrm{O}_{10}$ as Photocatalysts for Hydrogen Production From an

Aqueous Solution of Methanol.

Front. Chem. 8:300.

doi: $10.3389 /$ fchem.2020.00300

\section{Study of $\boldsymbol{n}$-alkylamine Intercalated Layered Perovskite-Like Niobates $\mathrm{HCa}_{2} \mathrm{Nb}_{3} \mathrm{O}_{10}$ as Photocatalysts for Hydrogen Production From an Aqueous Solution of Methanol}

\author{
Vladimir V. Voytovich, Sergei A. Kurnosenko, Oleg I. Silyukov*, Ivan A. Rodionov, \\ lana A. Minich and Irina A. Zvereva
}

Institute of Chemistry, Saint Petersburg State University, Saint Petersburg, Russia

A series of hybrid niobates $\mathrm{HCa}_{2} \mathrm{Nb}_{3} \mathrm{O}_{10} \times \mathrm{RNH}_{2}$, containing $n$-alkylamines $(\mathrm{R}=\mathrm{Me}$, Et, $\mathrm{Pr}, \mathrm{Bu}, \mathrm{Hx}, \mathrm{Oc}$ ) intercalated into the interlayer space, has been thoroughly studied concerning the photocatalytic hydrogen production from a model aqueous solution of methanol for the first time. All the hybrid photocatalysts were synthesized by the conventional ceramic technique followed by protonation and intercalation of $n$ alkylamines. The products were characterized using XRD, Raman, IR and diffuse reflectance spectroscopy, TGA, CHN-analysis and SEM. Photocatalytic measurements were conducted according to an advanced scheme taking into account possible changes in the photocatalyst concentration because of sedimentation, $\mathrm{pH}$ shifts and exfoliation of the samples into nanoplatelets. Special attention was also paid to the feasible improvement of the photocatalytic activity of the samples via their modification with Pt nanoparticles as a cocatalyst. In the series of amine derivatives, the highest rate of hydrogen generation was demonstrated by the Pt-loaded $\mathrm{HCa}_{2} \mathrm{Nb}_{3} \mathrm{O}_{10} \times \mathrm{BuNH}_{2}$ reaching apparent quantum efficiency of $13 \%$ in the $220-340 \mathrm{~nm}$ range. The initial $\mathrm{HCa}_{2} \mathrm{Nb}_{3} \mathrm{O}_{10}$ showed comparable efficiency of $8.3 \%$ that is greater than for other amine derivatives. It was demonstrated that for the investigated samples the photocatalytic activity correlates with their ability of water intercalation.

Keywords: photocatalysis, hydrogen, layered, perovskite, niobate, intercalation, amine, hybrid compounds

\section{INTRODUCTION}

The intensive consumption of energy resources such as petroleum and coal for the last decades is presently assumed as a reason for environmental degradation and the energy crisis, which forces the development of new renewable and more attractive from the environmental point of view alternative energy sources. The use of solar light as a renewable energy source has been lately intensified and, in particular, the photocatalytic water and organic substrates splitting are considered as an effective and ecologically friendly way of the hydrogen fuel production (Maeda, 2011). The most widely studied catalysts for photocatalytic water splitting are $\mathrm{TiO}_{2}$ and $\mathrm{TiO}_{2}$-based materials. Their activity, however, is often limited by a number of factors including the surface area and charge separation efficiency that justifies the research on new promising materials. Therefore, 
the class of layered materials with a perovskite-like structure including Dion-Jacobson (DJ) and Ruddlesden-Popper (RP) phases has been actively studied. Their structure may be presented as an alteration of perovskite blocks and interlayer cations with the general formulae $\mathrm{A}^{\prime}\left[\mathrm{A}_{\mathrm{n}-1} \mathrm{~B}_{\mathrm{n}} \mathrm{O}_{3 \mathrm{n}+1}\right]$ (for DJ) and $A_{2}^{\prime}\left[A_{n-1} B_{n} O_{3 n+1}\right]$ (for RP) (Machida et al., 2005; Compton et al., 2007; Huang et al., 2011; Chen et al., 2012; Rodionov et al., 2012, 2017; Sabio et al., 2012; Zvereva and Rodionov, 2013). These compounds are amenable to reactions involving their interlayer space, such as intercalation and ion exchange, which provide their unique photocatalytic properties (Zvereva et al., 2011; Silyukov et al., 2015; Rodionov et al., 2018; Shelyapina et al., 2019).

The main factors determining high efficiency of modern photocatalysts include narrowing of the bandgap into the visible light region, achieving high surface areas, crystallinity, a large number of catalytic sites and in addition realization of efficient charge separation. In accordance with these objectives, different approaches in preparation and modification of the catalysts have been applied, including cationic and anionic substitution and doping (Zou et al., 2001; Reddy et al., 2003; Kumar et al., 2011; Zhou et al., 2016; Kawashima et al., 2017), sensitization with dyes (Youngblood et al., 2009), intercalation of metals and other inorganic particles (Huang et al., 2006, 2009) as well as preparation of composites with other materials (Cui et al., 2012, 2013, 2014; Saito et al., 2016; Liu et al., 2018).

The hybrid inorganic-organic compounds form a promising class of materials which allows combining properties of preliminarily investigated inorganic and organic parts in order to prepare materials with new often unique properties which often differ from their original hosts (Sanchez, 2006; Kickelbick, 2007). Fabrication of these materials includes various strategies such as sol-gel and solvothermal bottom-up synthesis, dispersion selfassembly methods and intercalation chemistry approaches (Mir et al., 2018).

Practically, perovskite-like inorganic-organic hybrids may be prepared by insertion of organic molecules into their interlayer space while the hard structure of perovskite blocks remains unchanged. Such reactions are shown to proceed under soft chemistry conditions and usually require conventional or solvothermal/microwave-assisted heating and lead to the formation of inorganic-organic hybrids being stable to moderate physical and chemical impacts. The two main approaches to modify the interlayer space of perovskite-like oxides are presently known. The intercalation reactions with organic bases (usually amines) proceed through the acid-base mechanism, where positively charged ammonium ions interact with negatively charged perovskite blocks (Tsunoda et al., 2003; Shimizu et al., 2006; Wang et al., 2007). The grafting reactions involve the formation of strong ion-valence bonds between terminal interlayer oxygen atoms and organic molecules and may be described by the esterification-like mechanism (Tsunoda et al., 2003; Shimizu et al., 2006; Wang et al., 2007). The first example of the preparation of inorganic-organic amine intercalated compounds based on layered perovskite like oxide was presented for the DJ niobates (Jacobson et al., 1985, 1987) and later broadened by grafting reactions with methanol (Takahashi et al., 1995). By now, the number of various inorganic hosts with both
DJ and RP type of structure has been applied for preparation of inorganic-organic derivatives with a row of aliphatic and bulky amines and alcohols, amino alcohols, carboxylic acids, amino acids, carbohydrates, etc. (Hong and Kim, 1996; Han et al., 2001; Tsunoda et al., 2003; Tong et al., 2005; Takeda et al., 2006, 2008; Seiichi and Tahara, 2007; Tahara et al., 2007; Wang et al., 2012, 2018; Boykin and Smith, 2015; Shori et al., 2015; Sato et al., 2017; Silyukov et al., 2018).

However, despite the wide range of obtained inorganicorganic hybrids, lower attention has been paid to their functional properties, for instance, to the investigation of their photocatalytic activity. One of the possible reasons is the assumption of their low stability due to the photodegradation of inserted organic parts during the photocatalytic process. For example, the study on photocatalytic activity of the nhexylamine-intercalated DJ tantalate $\mathrm{HCa}_{2} \mathrm{Ta}_{3} \mathrm{O}_{10}$ has shown that modification of the interlayer space definitely leads to the enhancement of hydrogen evolution in the watersplitting reaction under ultraviolet light compared to the initial unmodified forms $\mathrm{MCa}_{2} \mathrm{Ta}_{3} \mathrm{O}_{10}(\mathrm{M}=\mathrm{Na}$, Cs, and $\mathrm{H})$ but the dramatic decrease in activity after the $8 \mathrm{~h}$ cycle was detected. This fact was explained by the degradation of the sample due to oxidation of the organic component which was confirmed by the decreased interlayer space and the insignificant oxygen evolution rate (Machida et al., 2005). The better results were achieved for $n$-alcohols grafted samples obtained from the RP type tantalate $\mathrm{H}_{2} \mathrm{CaTa}_{2} \mathrm{O}_{7}$ in reactions of rhodamine $\mathrm{B}$ and methyl orange decomposition under ultraviolet-visible irradiation (Wang et al., 2014). A series of $n$-alkoxy hybrids with organic chains containing $n=1,3,6,10,18$ carbon atoms has been tested and it was shown that, unlike short-chain alcohols, modification by long-chain alcohols $(n=10,18)$ significantly improves the photocatalytic activity of the samples. Another example of the preparation of hybrid catalysts based on niobates and titanates is polyaniline-intercalated compounds which proved themselves as effective catalysts in the visible light region in the decomposition of methylene blue reaction (Guo et al., 2010; Zhu et al., 2013; Liu et al., 2014). Such hybrids have also been obtained from some other layered perovskite-like oxides, though their photocatalytic activity has not been studied (Uma and Gopalakrishnan, 1994; Uma et al., 1995; Tong et al., 2005). One more approach for the preparation of visible-light catalysts was shown by Wang et al. who prepared carbon-intercalated composite by thermolysis of D-glucopyranose derivative of $\mathrm{HLaNb}_{2} \mathrm{O}_{7}$ which showed a narrowed bandgap comparing to the parent compound (Wang et al., 2012).

This study presents the results of the systematic investigation of the photocatalytic activity of a series of intercalated by $n$ amines niobates $\mathrm{HCa}_{2} \mathrm{Nb}_{3} \mathrm{O}_{10} \times \mathrm{RNH}_{2}$. $\mathrm{KCa}_{2} \mathrm{Nb}_{3} \mathrm{O}_{10}$ is a triplelayered niobate belonging to the $\mathrm{DJ}$ structural type with general formula $A^{\prime}\left[A_{n-1} B_{n} O_{3 n+1}\right]$ which was firstly prepared by Dion et al. (1981). The hydrated protonated form $\mathrm{HCa}_{2} \mathrm{Nb}_{3} \mathrm{O}_{10} \cdot \mathrm{yH}_{2} \mathrm{O}$ (usually presented as $\mathrm{HCa}_{2} \mathrm{Nb}_{3} \mathrm{O}_{10} \cdot 1.5 \mathrm{H}_{2} \mathrm{O}$ in the literature) is typically obtained by the ion-exchange reaction in acid solutions from the initial alkali form $\mathrm{KCa}_{2} \mathrm{Nb}_{3} \mathrm{O}_{10}$ (Jacobson et al., 1986). The structure of $\mathrm{KCN}_{3}$ may be described as an alternation of two-dimensional perovskite slabs, formed by 
the cubic array of corner-sharing $\mathrm{NbO}_{6}$ octahedra and $\mathrm{Ca}^{2+}$ ions in 12-coordinated sites in the center of each cube, whose structure remains upon protonation, and $\mathrm{K}^{+}$ions, which form so-called interlayer space and undergo substitution by protons (Fukuoka et al., 2000). As it was shown, the ion-exchanged phase $\mathrm{HCa}_{2} \mathrm{Nb}_{3} \mathrm{O}_{10} \cdot 1.5 \mathrm{H}_{2} \mathrm{O}$ undergoes further modification of the interlayer space by intercalation of amines (Jacobson et al., 1987) and may be exfoliated into nanoplatelets by intercalation of bulky organic bases with subsequent physical treatment such as shaking or sonication (Schaak and Mallouk, 2000; Ebina et al., 2002). In addition, the alkali form $\mathrm{KCa}_{2} \mathrm{Nb}_{3} \mathrm{O}_{10}$, its protonated form $\mathrm{HCa}_{2} \mathrm{Nb}_{3} \mathrm{O}_{10} \cdot 1.5 \mathrm{H}_{2} \mathrm{O}$ and their exfoliated and restacked composites have been studied as promising highly efficient photocatalytic materials (Domen et al., 1993; Sabio et al., 2012; Oshima et al., 2014).

Although this triple-layered DJ niobate has been widely studied as a starting material for the preparation of inorganicorganic hybrids, the investigations on their photocatalytic properties are not presented in the literature. Based on the limited works performed for other compounds, several important points remain unclear. In particular, it should be further clarified whether the obtained inorganic-organic hybrids may be stable under special conditions during the photocatalytic process and lead to its promotion, or the intercalated organic components, in any case, undergo the photodegradation. Therefore, our work focuses on the synthesis and photocatalytic properties of the $n$-alkylamine modified niobates $\mathrm{HCa}_{2} \mathrm{Nb}_{3} \mathrm{O}_{10} \times \mathrm{RNH}_{2}$ as examples of hybrid inorganic-organic layered materials obtained via the intercalation reaction. Their photocatalytic activity was investigated in the reaction of hydrogen evolution from an aqueous methanol solution under ultraviolet radiation and compared with the initial oxide $\mathrm{HCa}_{2} \mathrm{Nb}_{3} \mathrm{O}_{10} \cdot \mathrm{yH}_{2} \mathrm{O}$.

\section{MATERIALS AND METHODS}

\section{Synthesis}

$\mathrm{KCa}_{2} \mathrm{Nb}_{3} \mathrm{O}_{10}\left(\mathrm{KCN}_{3}\right)$

The initial perovskite-like niobate $\mathrm{KCN}_{3}$ was synthesized by the standard ceramic method in the air atmosphere at atmospheric pressure using $\mathrm{CaO}, \mathrm{Nb}_{2} \mathrm{O}_{5}$, and $\mathrm{K}_{2} \mathrm{CO}_{3}$ as reactants:

$4 \mathrm{CaO}+3 \mathrm{Nb}_{2} \mathrm{O}_{5}+\mathrm{K}_{2} \mathrm{CO}_{3}=2 \mathrm{KCa}_{2} \mathrm{Nb}_{3} \mathrm{O}_{10}+\mathrm{CO}_{2} \uparrow$

Amounts of oxides $\mathrm{CaO}$ and $\mathrm{Nb}_{2} \mathrm{O}_{5}$ were taken according to the stoichiometry of the reaction, potassium carbonate $\mathrm{K}_{2} \mathrm{CO}_{3}$ with a $30 \%$ excess. All components were mixed and ground in the planetary-ball mill under a layer of $n$-heptane. The powder obtained was pelletized into $\sim 2 \mathrm{~g}$ tablets. The tablets were calcined at $800^{\circ} \mathrm{C}$ for $12 \mathrm{~h}$, ground in an agate mortar, pelletized again and calcined at $1,100^{\circ} \mathrm{C}$ for $24 \mathrm{~h}$.

\section{$\mathrm{HCa}_{2} \mathrm{Nb}_{3} \mathrm{O}_{10} \cdot \mathrm{yH}_{2} \mathrm{O}\left(\mathrm{HCN}_{3} \cdot \mathrm{yH}_{2} \mathrm{O}\right)$}

The protonated form of the niobate was prepared by acid treatment of $\mathrm{KCN}_{3}$ with an excess of $12 \mathrm{M} \mathrm{HNO}_{3}(50 \mathrm{ml}$ per $2.5 \mathrm{~g}$ of the oxide) at room temperature for $24 \mathrm{~h}$. After this, the product was centrifuged, washed with $50 \mathrm{ml}$ of water three times to remove acid residues and dried under ambient pressure. Subsequent storage of $\mathrm{HCN}_{3} \cdot \mathrm{yH}_{2} \mathrm{O}$ was carried out in an atmosphere of humid air to prevent dehydration.
TABLE 1 | Conditions of the $\mathrm{HCN}_{3} \times \mathrm{RNH}_{2}$ preparation

\begin{tabular}{lccc}
\hline $\mathbf{R}$ & Amine concentration, \% & Temperature, ${ }^{\circ} \mathbf{C}$ & Duration, d \\
\hline $\mathrm{Me}$ & 38 (in water) & & \\
\hline $\mathrm{Et}$ & 70 (in water) & & 1 \\
$\mathrm{Pr}$ & 90 (in water) & 25 & \\
$\mathrm{Bu}$ & & & 7 \\
\hline $\mathrm{Hx}$ & 100 & 60 & \\
\hline $\mathrm{Oc}$ & 30 (in $n$-heptane) & &
\end{tabular}

\section{$\mathrm{HCa}_{2} \mathrm{Nb}_{3} \mathrm{O}_{10} \times \mathrm{RNH}_{2}\left(\mathrm{HCN}_{3} \times \mathrm{RNH}_{2}\right)$}

For the synthesis of $n$-alkylamine derivatives $\mathrm{HCN}_{3} \times \mathrm{RNH}_{2}$ $(\mathrm{R}=\mathrm{Me}, \mathrm{Et}, \mathrm{Pr}, \mathrm{Bu}, \mathrm{Hx}$, and $\mathrm{Oc})$, in each case, $0.25 \mathrm{~g}$ of the protonated form $\mathrm{HCN}_{3} \cdot \mathrm{yH}_{2} \mathrm{O}$ was stirred with $10 \mathrm{ml}$ of the amine solution in a sealed glass tube in accordance with the conditions shown in Table 1. Afterwards, each product was filtered, rinsed with acetone to remove residual adsorbed amines, dried under ambient pressure and analyzed via the following methods.

\section{Characterization XRD Analysis}

Powder X-ray diffraction (XRD) patterns were obtained on the Rigaku Miniflex II diffractometer $\left(\mathrm{CuK}_{\alpha}\right.$ radiation, angle range $2 \theta=3-60^{\circ}$, scanning rate $10 \% / \mathrm{min}$, step $0.02^{\circ}$ ). The lattice parameters were calculated in the tetragonal system on the basis of all the reflections observed using DiffracPlus Topas software. During indexing, estimated space groups were also determined.

\section{Raman Spectroscopy}

Raman scattering spectra were collected on the Bruker Senterra spectrometer (spectral range 100-4,000 $\mathrm{cm}^{-1}$, incident laser $488 \mathrm{~nm} 20 \mathrm{~mW}$, spectrum accumulation time $10 \mathrm{~s}$ ).

\section{IR Spectroscopy}

Fourier-transformed infrared (IR) absorption spectra were recorded on the Shimadzu IRAffinity-1 spectrometer (spectral range $400-4,000 \mathrm{~cm}^{-1}$, tableting in $\mathrm{KBr}$ ).

\section{TG Analysis}

Thermogravimetric (TG) analysis of the samples was carried out on the Netzsch TG 209 F1 Libra thermobalance in an oxidative atmosphere (temperature range $30-950^{\circ} \mathrm{C}$, heating rate $\left.10^{\circ} \mathrm{C} / \mathrm{min}\right)$.

\section{CHN Analysis}

The amounts of carbon, hydrogen, and nitrogen in $n$ alkylamine derivatives were determined using the Euro EA3028HT analyzer.

\section{Diffuse Reflectance Spectroscopy}

Diffuse reflectance spectroscopy (DRS) of the samples was performed on the Shimadzu UV-2550 spectrophotometer with the ISR-2200 integrating sphere attachment. Optical bandgap energies of the samples were found via transformation of reflectance spectra into coordinates $(F \cdot h \nu)^{1 / 2}=f(h \nu)$, where $\mathrm{F}$ is the Kubelka-Munk function, and further determination 
of abscissas of the intersection points of linear sections of the graphs.

\section{SEM}

The morphology of the samples was investigated on the Zeiss Merlin scanning electron microscope (SEM) with a field emission cathode, an electron optics column GEMINI-II and an oil-free vacuum system.

\section{Vacuum Stability}

To investigate the stability of $n$-alkylamine derivatives at reduced pressure, their hitches of $50 \mathrm{mg}$ were placed in a desiccator with the oil vacuum pump Edwards E2M1.5 and held under residual pressure of $10^{-4}$ atm for 5 and $10 \mathrm{~d}$. Compositions of the resulting samples were determined via the $\mathrm{CHN}$-analysis.

\section{Specific Surface Area}

Specific surface areas of the samples were measured by the BET method on the Micromeritics ASAP 2020MP system with the previous vacuum degassing at room temperature using $\mathrm{N}_{2}$ and $\mathrm{Kr}$ as adsorbates.

\section{Stability in Water}

To investigate the resistance of $n$-alkylamine derivatives to hydrolysis, their hitches of $50 \mathrm{mg}$ were placed into sealed glass tubes with $10 \mathrm{ml}$ of water and stirred for 1 and $10 \mathrm{~d}$ at room temperature. After this, samples were filtered and analyzed by XRD and, in some cases, Raman spectroscopy.

\section{Photocatalytic Experiments}

\section{Study of the Hydrogen Generation Kinetics}

Photocatalytic activity of the samples was measured in the reaction of light-driven hydrogen evolution from an aqueous solution of methanol. The photocatalytic equipment, as well as the experimental conditions, were the same as in our previous work (Rodionov et al., 2019).

To prepare the suspension for the photocatalytic experiment, $30 \mathrm{mg}$ of the sample was added to $60 \mathrm{ml}$ of $1 \mathrm{~mol}$. \% methanol. The mixture was shaken and left for $10 \mathrm{~min}$ to establish equilibrium between the photocatalyst and the solution. Then it was sonicated for $10 \mathrm{~min}$ in the Elmasonic $\mathrm{S} 10 \mathrm{H}$ ultrasound bath to disaggregate the photocatalyst particles.

The suspension obtained $(50 \mathrm{ml})$ was placed in the external irradiation reaction cell, equipped with a magnetic stirrer and a liquid cut-off-filter and connected to a closed gas circulation system (120 ml dead volume). A medium-pressure mercury lamp DRT-125 $(125 \mathrm{~W})$ was used as a radiation source. The light was reaching the reaction cell only after passing through a light filter solution $(\mathrm{KCl}+\mathrm{NaBr}, 6 \mathrm{~g} / \mathrm{L}$ of each salt, $2 \mathrm{~cm}$ optical path) thermostated at $15^{\circ} \mathrm{C}$, which cuts off radiation with $\lambda<220 \mathrm{~nm}$. During the photocatalytic reaction, hydrogen was accumulating in the gas phase, the composition of which was analyzed by the online gas chromatograph (Shimadzu GC-2014, Rt-Msieve 5A Column, TCD, Ar carrier) at certain time intervals. At the beginning of the experiment, the system was deaerated and argon was introduced at atmospheric pressure.

The $\mathrm{pH}$ of the suspension and its concentration $\mathrm{c}(\mathrm{mg} / \mathrm{l})$ determined from its ultraviolet-visible (UV-vis) transmission spectra were measured at the beginning of the photocatalytic experiment $\left(\mathrm{pH}_{1}, \mathrm{c}_{1}\right)$, in the ending $\left(\mathrm{pH}_{2}, \mathrm{c}_{2}\right)$ and after centrifuging of the suspension at $1000 \mathrm{RCF}$ for $1 \mathrm{~h}\left(\mathrm{pH}_{3}\right.$, $\mathrm{c}_{3}$ ) to take into account a possible change of the suspension concentration during the photocatalytic experiment and potential exfoliation of the sample into nanoplatelets.

The apparent quantum efficiency of hydrogen generation $\phi$ was calculated by the formula $\phi=\omega / \omega_{0}$, where $\omega$ is the observed hydrogen evolution rate and $\omega_{0}$ is the theoretical maximum hydrogen evolution rate if we assume that all incident photons with energy greater than bandgap $\mathrm{E}_{\mathrm{g}}$ are absorbed with generation of electron-hole pairs, which subsequently lead to hydrogen reduction and alcohol oxidation with a $100 \%$ yield without recombination and other side-reactions. For the experimental setup used, $\omega_{0}=7.5 \mathrm{mmol} / \mathrm{h}$ was previously determined via the ferrioxalate actinometry technique (Rodionov et al., 2019).

All the photocatalytic measurements were performed both without a cocatalyst addition and with loading 1 mass. \% Pt cocatalyst via in situ photocatalytic platinization. In the latter case $1.1 \mathrm{ml}$ of $2.56 \mathrm{mmol} / \mathrm{L} \mathrm{H}_{2} \mathrm{PtCl}_{6}$ aqueous solution was added to $54 \mathrm{ml}$ of the reaction mixture before the experiment. After $15 \mathrm{~min}$ of irradiation under argon flushing conditions, a suspension sample of $4 \mathrm{ml}$ was taken to photometrically measure the concentration of platinized particles in the suspension. Additional argon flushing was performed for $15 \mathrm{~min}$ to exclude air components from the system and then the system was closed and the measurement was started.

\section{Suspension Concentration and $\mathrm{pH}$ Measurements}

In order to determine the concentration of photocatalytic suspensions before, after the experiment and after their centrifuging, their UV-vis spectra were recorded on the Thermo Scientific Genesys 10S UV-Vis spectrophotometer at the spectral range of $190-1,100 \mathrm{~nm}$. If necessary, suspensions were diluted to achieve optical density $\mathrm{A}<1$ at the maximum of the most intense band. To determine their concentrations (mg/l) from UV-vis spectra, spectrophotometric calibration plots for suspensions of non-exfoliated (bulk) and exfoliated into nanoplatelets niobate were previously built as it is described in the Supporting Information S1.

$\mathrm{pH}$ values of the photocatalytic suspensions were determined using the Mettler Toledo S220 SevenCompact pH-meter equipped with the InLabExpert Pro-ISM before, after the experiment and also after their centrifuging after the experiment.

\section{RESULTS AND DISCUSSION}

\section{Characterization of the Samples}

According to data of the powder XRD analysis (Figure 1), protonated layered perovskite-like niobate $\mathrm{HCN}_{3} \cdot \mathrm{yH}_{2} \mathrm{O}$ was successfully obtained in a single-phase form and its lattice parameters were found to be in good consistency with the literature values (Jacobson et al., 1986; Tahara and Sugahara, 2003). Reactions of $\mathrm{HCN}_{3} \cdot \mathrm{yH}_{2} \mathrm{O}$ with $n$-alkylamines lead to a series of single-phase amine derivatives with greater $c$ parameters because of intercalation of amines into the interlayer space. In 


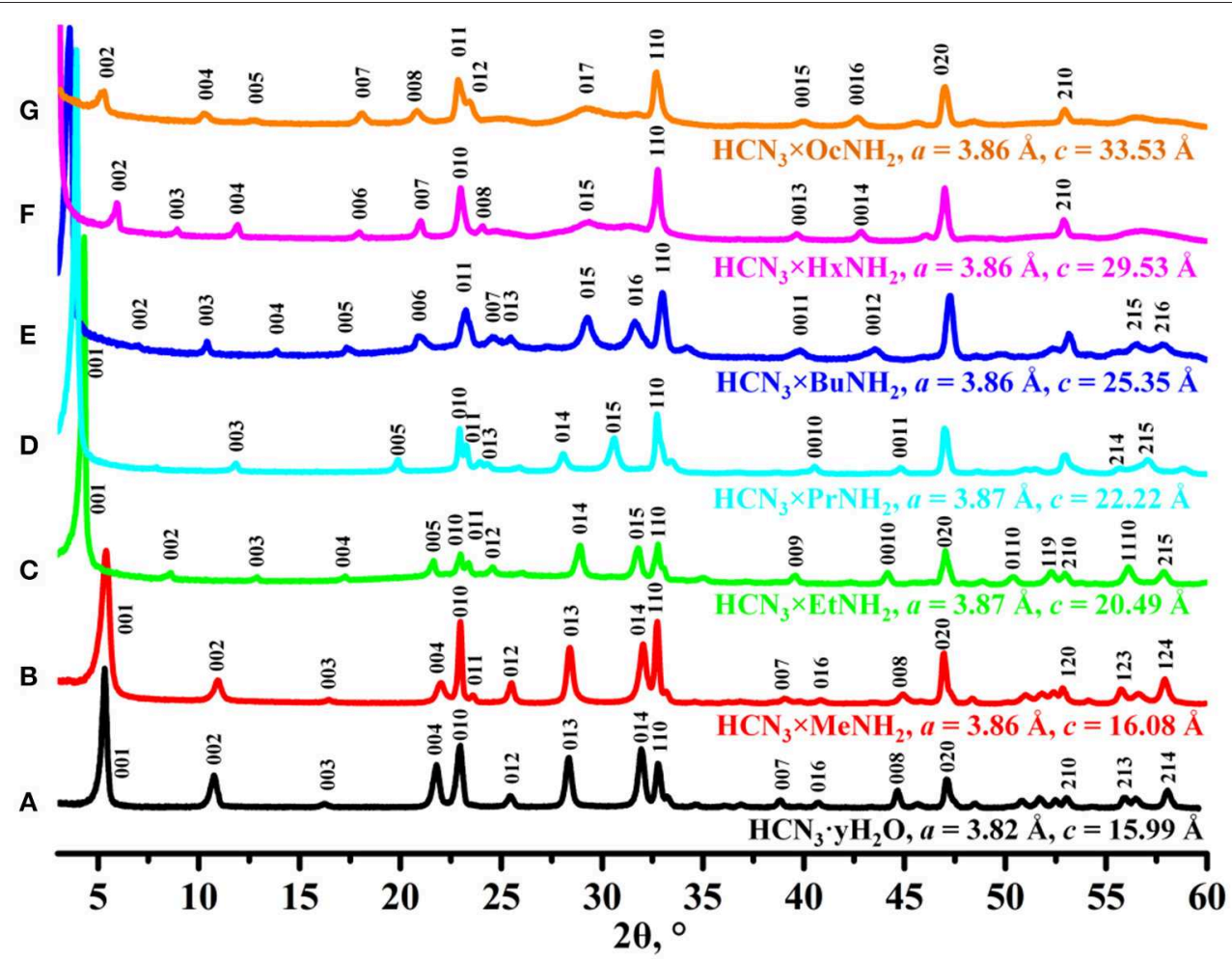

FIGURE 1 | X-ray diffraction patterns and unit cell parameters indexed in tetragonal system (P4/mmm) of (A) $\mathrm{HCN}_{3} \cdot \mathrm{yH} \mathrm{H}_{2} \mathrm{O}$, (B) $\mathrm{HCN}_{3} \times \mathrm{MeNH}_{2}$, (C) $\mathrm{HCN}_{3} \times E t N H_{2}$, (D) $\mathrm{HCN}_{3} \times \mathrm{PrNH}_{2}$, (E) $\mathrm{HCN}_{3} \times \mathrm{BuNH}_{2}$, (F) $\mathrm{HCN}_{3} \times \mathrm{HxNH}_{2}$, (G) $\mathrm{HCN}_{3} \times \mathrm{OCNH}_{2}$.

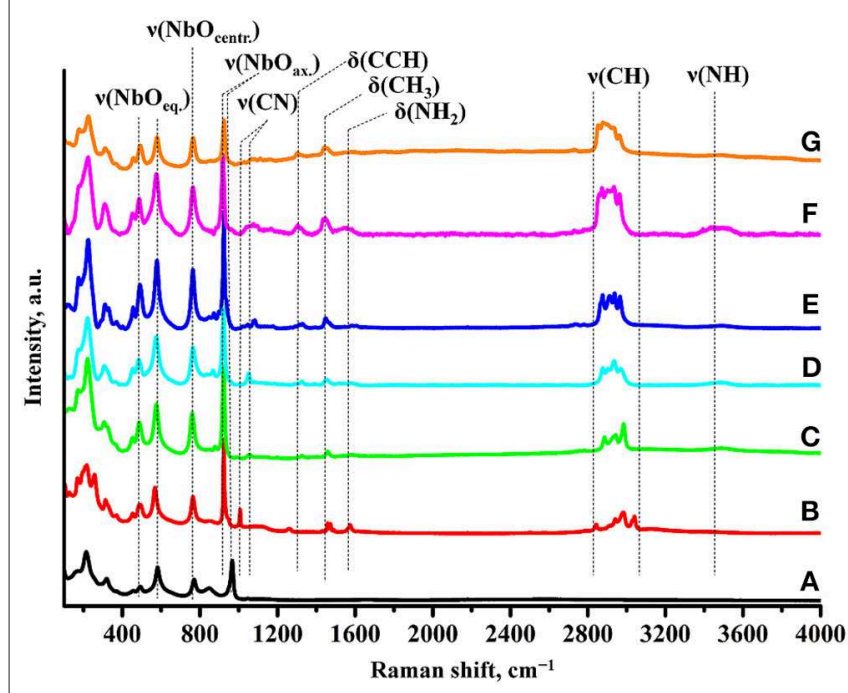

FIGURE 2 | Raman spectra of (A) $\mathrm{HCN}_{3} \cdot y \mathrm{H}_{2} \mathrm{O}$, (B) $\mathrm{HCN}_{3} \times \mathrm{MeNH}_{2}$, (C) $\mathrm{HCN}_{3} \times \mathrm{EtNH}_{2}$, (D) $\mathrm{HCN}_{3} \times \mathrm{PrNH}_{2}$, (E) $\mathrm{HCN}_{3} \times \mathrm{BuNH}_{2}$, (F) $\mathrm{HCN}_{3} \times \mathrm{H} \times \mathrm{NH}_{2}$, (G) $\mathrm{HCN}_{3} \times \mathrm{OCNH}_{2}$.

general, the $c$ lattice parameter, which is known to correspond to the interlayer distance of the sample (Silyukov et al., 2018; Kurnosenko et al., 2019), was found to be proportional to the length of the $n$-alkylamine chain that consists with earlier reports

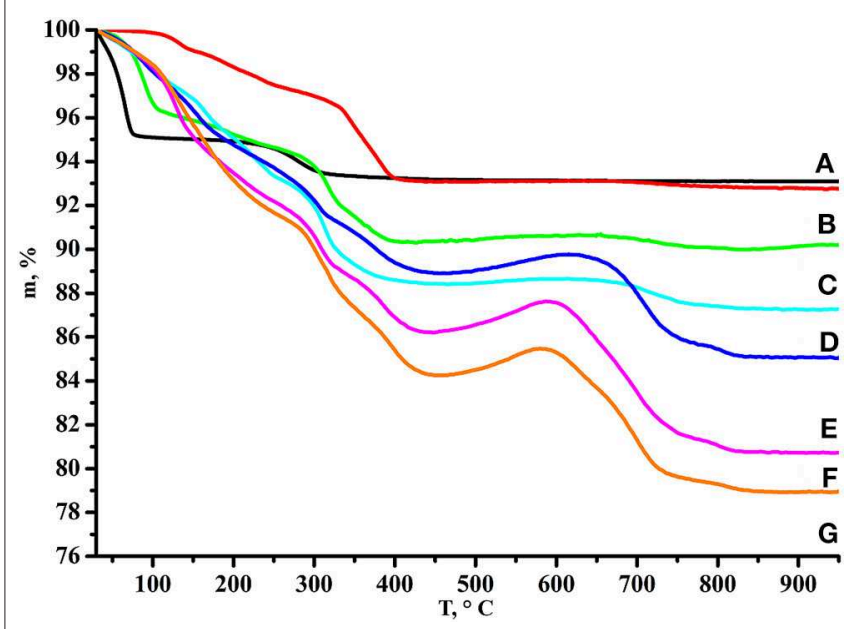

FIGURE 3 | TG curves of (A) $\mathrm{HCN}_{3} \cdot y \mathrm{H}_{2} \mathrm{O}$, (B) $\mathrm{HCN}_{3} \times \mathrm{MeNH}_{2}$, (C) $\mathrm{HCN}_{3} \times \mathrm{EtNH}_{2}$, (D) $\mathrm{HCN}_{3} \times \mathrm{PrNH}_{2}$, (E) $\mathrm{HCN}_{3} \times \mathrm{BuNH}_{2}$, (F) $\mathrm{HCN}_{3} \times \mathrm{HxNH}_{2}$, (G) $\mathrm{HCN}_{3} \times \mathrm{OCNH}_{2}$.

(Jacobson et al., 1986; Tahara and Sugahara, 2003; Kurnosenko et al., 2019; Rodionov et al., 2019). Since all the samples were successfully indexed in the $\mathrm{P} 4 / \mathrm{mmm}$ group without doubling of the $c$ lattice parameter, we suppose that intercalation of amines did not cause a relative shift of adjacent perovskite slabs which is absent in the case of the initial protonated niobate $\mathrm{HCN}_{3} \cdot \mathrm{yH}_{2} \mathrm{O}$. 
Formation of the amine derivatives is clearly seen from their Raman spectra (Figure 2). It is accompanied by appearance of characteristic bands relating to latitudinal vibrations of $\mathrm{C}-\mathrm{C}-\mathrm{H} \quad\left(1,310 \mathrm{~cm}^{-1}\right)$, methyl $\left(1,445 \mathrm{~cm}^{-1}\right)$, and amino $\left(1,575 \mathrm{~cm}^{-1}\right)$ fragments as well as stretching of C-N (1,010$\left.1,080 \mathrm{~cm}^{-1}\right), \mathrm{C}-\mathrm{H}\left(2,820-3,060 \mathrm{~cm}^{-1}\right)$, and $\mathrm{N}-\mathrm{H}(3,430-$ $\left.3,530 \mathrm{~cm}^{-1}\right)$ bonds. Intercalation of amines also results in the shift of the axial $\mathrm{Nb}-\mathrm{O}$ stretching mode from 965 to $925 \mathrm{~cm}^{-1}$. Unlike the Ruddlesden-Popper titanates (Rodionov et al., 2019), this band does not undergo noticeable splitting into two new bands indicating that all niobium-oxygen octahedra adjacent to the interlayer space possess equal axial $\mathrm{Nb}-\mathrm{O}$ distances, i.e., almost all the interlayer protons of the initial niobate are associated with molecules of amines. At the same time, stretching modes of equatorial (490, $\left.580 \mathrm{~cm}^{-1}\right)$ and located in central octahedra $\left(765 \mathrm{~cm}^{-1}\right)$ $\mathrm{Nb}-\mathrm{O}$ fragments are seen not to be influenced by the amines introduction into the inorganic matrix. IR spectra (Supporting Information S2) also confirm the formation of the derivatives and point at the presence of water molecules in the interlayer space $\left(1,625 \mathrm{~cm}^{-1}\right)$ that is typical of other amine-modified compounds (Silyukov et al., 2018; Kurnosenko et al., 2019; Rodionov et al., 2019) due to formation of strong hydrogen bonds.

TABLE 2 | Quantitative compositions of the samples $\left(\mathrm{HCN}_{3} \cdot \mathrm{xRNH}_{2} \cdot \mathrm{yH} \mathrm{H}_{2} \mathrm{O}\right)$ and their light absorption characteristics.

\begin{tabular}{lccccc}
\hline Sample & $\mathbf{x}\left(\mathbf{R N H}_{\mathbf{2}}\right)$ & $\mathbf{y}\left(\mathbf{H}_{\mathbf{2}} \mathbf{O}\right)$ & Total mass loss, $\%$ & $\mathbf{E}_{\mathbf{g}}, \mathbf{e V}$ & $\lambda_{\max }, \mathbf{n m}$ \\
\hline $\mathrm{HCN}_{3} \cdot \mathrm{yH}_{2} \mathrm{O}$ & - & 1.5 & 6.86 & 3.49 & 355 \\
$\mathrm{HCN}_{3} \times \mathrm{MeNH}_{2}$ & 0.94 & 0.09 & 7.23 & 3.56 & 348 \\
$\mathrm{HCN}_{3} \times \mathrm{EtNH}_{2}$ & 0.97 & 0.23 & 9.98 & 3.60 & 344 \\
$\mathrm{HCN}_{3} \times \mathrm{PrNH}_{2}$ & 0.99 & 0.40 & 12.75 & 3.55 & 349 \\
$\mathrm{HCN}_{3} \times \mathrm{BuNH}_{2}$ & 1.00 & 0.45 & 14.95 & 3.62 & 343 \\
$\mathrm{HCN}_{3} \times \mathrm{HxNH}_{2}$ & 1.06 & 0.33 & 19.27 & 3.55 & 349 \\
$\mathrm{HCN}_{3} \times \mathrm{OcNH}_{2}$ & 0.94 & 0.31 & 21.06 & 3.60 & 344
\end{tabular}

Processing of the TG curve (Rodionov et al., 2017, 2019) corresponding to the initial protonated niobate (Figure 3) confirmed that $\mathrm{HCN}_{3} \cdot \mathrm{yH}_{2} \mathrm{O}$ does not contain residual potassium cations from the alkali precursor $\mathrm{KCN}_{3}$ and exists in the hydrated form $\mathrm{HCN}_{3} \cdot 1.5 \mathrm{H}_{2} \mathrm{O}$. Thus, its thermal decomposition proceeds in two steps: deintercalation of the interlayer water $\left(30-70^{\circ} \mathrm{C}\right)$ and topochemical condensation of the inorganic matrix (250$350^{\circ} \mathrm{C}$ ) with the formation of $\mathrm{Ca}_{2} \mathrm{Nb}_{3} \mathrm{O}_{9.5}$. Mass losses of the $n$-alkylamine derivatives are proportional to molecular masses of intercalated amines and their TG curves demonstrate much more complex behavior. At the first stage $\left(50-400^{\circ} \mathrm{C}\right)$ deintercalation of amines and water takes place giving significant mass loss. After a temperature of $\sim 450^{\circ} \mathrm{C}$ is reached, mass begins to rise that is more pronounced in the case of heavier amines. This mass gain points out that even at such a high temperature some carboncontaining species are still remaining and that at $450-600^{\circ} \mathrm{C}$ they undergo partial oxidation. Further heating, apparently, leads to their burning which explains the consequent mass decrease.

Compositions of the derivatives calculated on the basis of TG and CHN-analysis data are presented in Table 2 in the form $\mathrm{HCN}_{3} \cdot \mathrm{xRNH}_{2} \cdot \mathrm{yH}_{2} \mathrm{O}$. As one can see from the table, the amount of each intercalated amine is approximately equal to the number of protons from the initial protonated form $(\sim 1: 1)$ that conforms to the absence of the axial $\mathrm{Nb}-\mathrm{O}$ band splitting in the Raman spectra (Figure 2).

Table 2 contains optical bandgap energies $E_{\mathrm{g}}$ of the samples calculated from their transformed diffuse reflectance spectra (Supporting Information S3) and corresponding maximum wavelengths $\lambda_{\max }$ of absorbed light. According to the presented data, all the samples mainly absorb the radiation of the nearultraviolet region and intercalation of amines slightly increases the $E_{\mathrm{g}}$ value because of the interlayer space expansion (Rodionov et al., 2017). Thus, there is no factor of different amounts of available light that could otherwise explain the difference in observed photocatalytic activity of the samples.

According to SEM images of the samples (Supporting Information S4), their particles are presented as intergrown lamellar polycrystals possessing linear sizes of
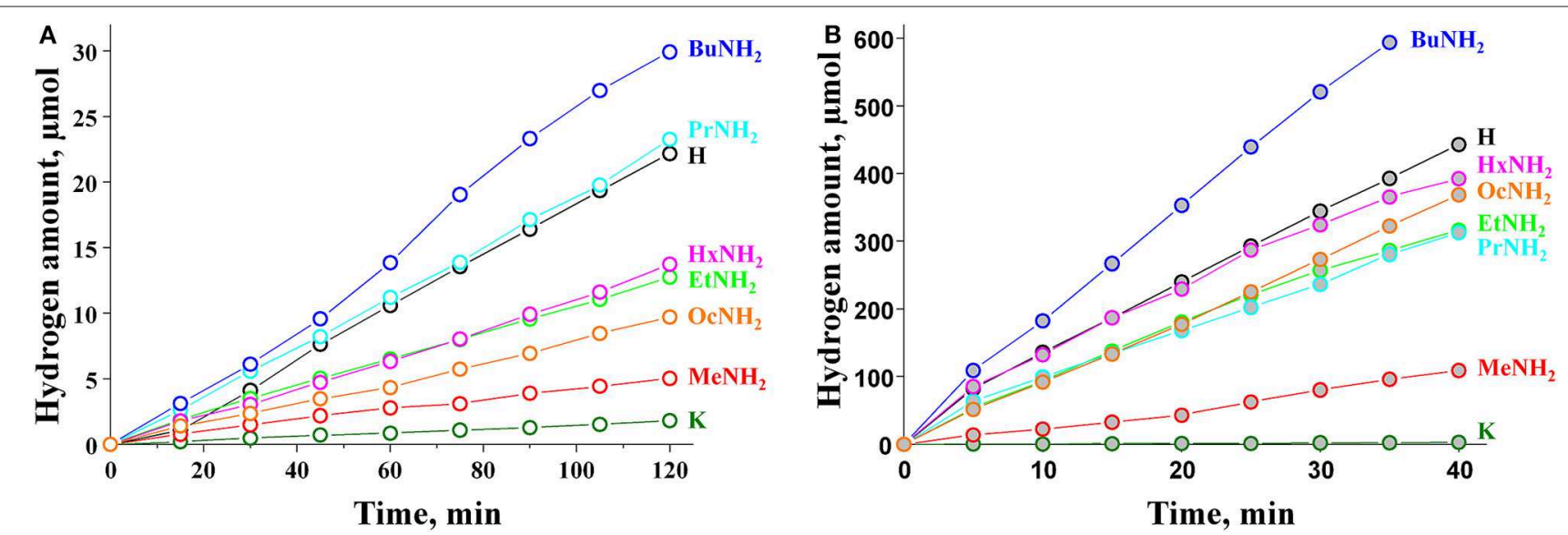

FIGURE 4 | Kinetic curves of photocatalytic hydrogen evolution over (A) bare and (B) platinized $\mathrm{KCN}_{3}, \mathrm{HCN}_{3} \cdot \mathrm{yH}_{2} \mathrm{O}$, and $\mathrm{HCN}_{3} \times \mathrm{RNH}_{2}$. 
$0.5-2.5 \mu \mathrm{m}$ and thickness of $150-500 \mathrm{~nm}$ that is typical of ceramic layered oxides. Moreover, intercalation of amines does not greatly affect the morphology of particles that is due to the topochemical mechanism of the aforementioned reaction.

Prior to the measurement of specific surface areas by BET, the stability of the amine derivatives under vacuum conditions was studied. Supporting Information S5 summarizes amounts of intercalated amines per formula unit in the initial derivatives as well as in the samples kept for 5 and $10 \mathrm{~d}$ under residual pressure of $10^{-4} \mathrm{~atm}$. As one can see from the table, the amine content in most cases remains virtually unchanged. It means $n$ alkylamine derivatives $\mathrm{HCN}_{3} \times \mathrm{RNH}_{2}$ are stable under reduced pressure and may be investigated by BET and other methods requiring previous degassing at room temperature. High stability of the compounds is, apparently, connected with strong ionic bonding between interlayer amines and the inorganic matrix.

All the samples studied by $\mathrm{BET}\left(\mathrm{HCN}_{3} \cdot \mathrm{yH}_{2} \mathrm{O}\right.$, $\mathrm{HCN}_{3} \times \mathrm{MeNH}_{2}, \quad \mathrm{HCN}_{3} \times \mathrm{OcNH}_{2}$ ) possess a small specific surface area that is typical of ceramic oxide materials. Since BET

TABLE 3 | Rate of photocatalytic hydrogen evolution $(\omega)$ and its apparent quantum efficiency at $220-340 \mathrm{~nm}(\phi)$ from $1 \mathrm{~mol}$. \% aqueous methanol solution.

\begin{tabular}{|c|c|c|c|c|}
\hline \multirow[t]{2}{*}{ Photocatalyst } & \multicolumn{2}{|c|}{ Bare photocatalyst } & \multicolumn{2}{|c|}{ Pt-loaded photocatalyst } \\
\hline & $\omega, \mathrm{mmol} / \mathrm{h}$ & $\phi, \%$ & $\omega, \mathrm{mmol} / \mathrm{h}$ & $\phi, \%$ \\
\hline $\mathrm{KCN}_{3}$ & 0.0009 & 0.012 & 0.005 & 0.072 \\
\hline $\mathrm{HCN}_{3}$ & 0.012 & 0.16 & 0.62 & 8.3 \\
\hline $\mathrm{HCN}_{3} \times \mathrm{MeNH}_{2}$ & 0.0024 & 0.032 & 0.17 & 2.3 \\
\hline $\mathrm{HCN}_{3} \times \mathrm{EtNH}_{2}$ & 0.0061 & 0.082 & 0.46 & 6.1 \\
\hline $\mathrm{HCN}_{3} \times \mathrm{PrNH}_{2}$ & 0.012 & 0.16 & 0.43 & 5.7 \\
\hline $\mathrm{HCN}_{3} \times \mathrm{BuNH}_{2}$ & 0.016 & 0.22 & 0.99 & 13 \\
\hline $\mathrm{HCN}_{3} \times \mathrm{HxNH}_{2}$ & 0.0069 & 0.091 & 0.54 & 7.2 \\
\hline $\mathrm{HCN}_{3} \times \mathrm{OcNH}_{2}$ & 0.0048 & 0.064 & 0.55 & 7.3 \\
\hline
\end{tabular}

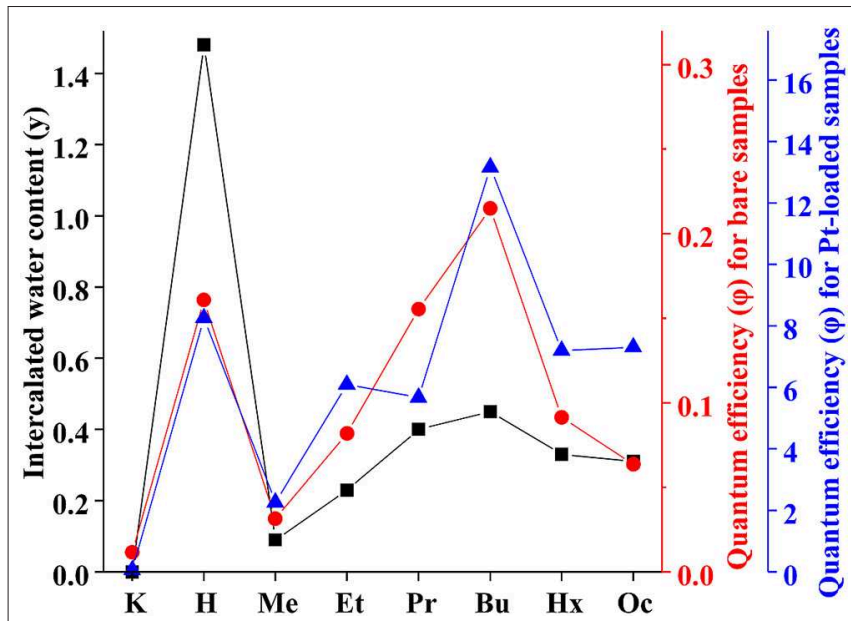

FIGURE 5 | Correlation between apparent quantum efficiency of photocatalytic hydrogen evolution over $\mathrm{KCN}_{3}, \mathrm{HCN}_{3} \cdot \mathrm{yH} \mathrm{H}_{2} \mathrm{O}$, and $\mathrm{HCN}_{3} \times \mathrm{RNH}_{2}$ and intercalated water content (y). measurements in this range are carried out with a relatively high error, we present data obtained with two different adsorbates (Supporting Information S6). According to the results, protonation and formation of the $n$-alkylamine derivatives are not accompanied by a noticeable change in the specific surface area (that is consistent with minor changes in the morphology of the samples noted by the results of SEM) and, consequently, this factor should not be the main reason for differences in their photocatalytic properties.

Comparison of XRD patterns of initial amine derivatives and products obtained via their water treatment (Supporting Information S7) showed that methylamine- and ethylamine-containing samples do not undergo any noticeable changes in the interlayer distance since their $(00 \mathrm{x})$ reflections preserve initial positions indicating maintaining the $c$ lattice parameter. Preservation of organic components in these samples was also confirmed by characteristic bands in their Raman spectra (not shown). However, water treatment of the $n$-propylamine derivative lead to the formation of new by-phases that may be explained by partial leaching of $n$-propylamine or additional hydration of the interlayer space. Keeping of the $n$-butylamine derivative in water for $10 \mathrm{~d}$ gave a new phase with significantly increased interlayer distance. Such expansion of the interlayer space should be due to its strong hydration. In the case of $n$-hexylamine and $n$-octylamine derivatives, structural changes during water treatment are practically absent. This fact may be connected with the low polarity of long-chain $n$ alkylamines which makes intercalation of polar water molecules a thermodynamically unprofitable process.

\section{Photocatalytic Activity}

The results of photocatalytic experiments are presented in Figure 4. The kinetic curves demonstrate almost linear behavior during the time of measurement (120 min for bare samples and $40 \mathrm{~min}$ for Pt-loaded samples). The hydrogen evolution rate $\omega$ was calculated for each sample from the slope of the kinetic curve. These data, together with the calculated values of apparent quantum efficiency $\phi$, are collected in Table 3. The standard error of the hydrogen evolution rate determined is estimated at $7 \%$.

The initial potassium niobate $\mathrm{KCN}_{3}$ showed poor photocatalytic activity with a quantum efficiency of hydrogen evolution as low as $0.012 \%$. However, after protonation, this value increased ca. 14 -fold and reached $0.16 \%$ for the $\mathrm{HCN}_{3}$ sample. This effect is already known from the literature (Domen et al., 1993) and is explained by the capability of the protonated form to reversibly intercalate water into the interlayer space, which is considered a separate reaction zone for the oxidation half-reaction. Our study supports this data, showing that the $\mathrm{HCN}_{3}$ sample contains 1.5 water molecules per formula unit (Table 2). $\mathrm{KCN}_{3}$, however, does not intercalate water at ambient conditions.

By analogy with the triple-layered titanate $\mathrm{H}_{2} \mathrm{Nd}_{2} \mathrm{Ti}_{3} \mathrm{O}_{10}$ (Rodionov et al., 2019), we expected the photocatalytic activity to rise significantly after the $n$-alkylamines intercalation. However, it was not quite the case. We see that the methylamine sample $\mathrm{HCN}_{3} \times \mathrm{MeNH}_{2}$ shows 4 times lower 


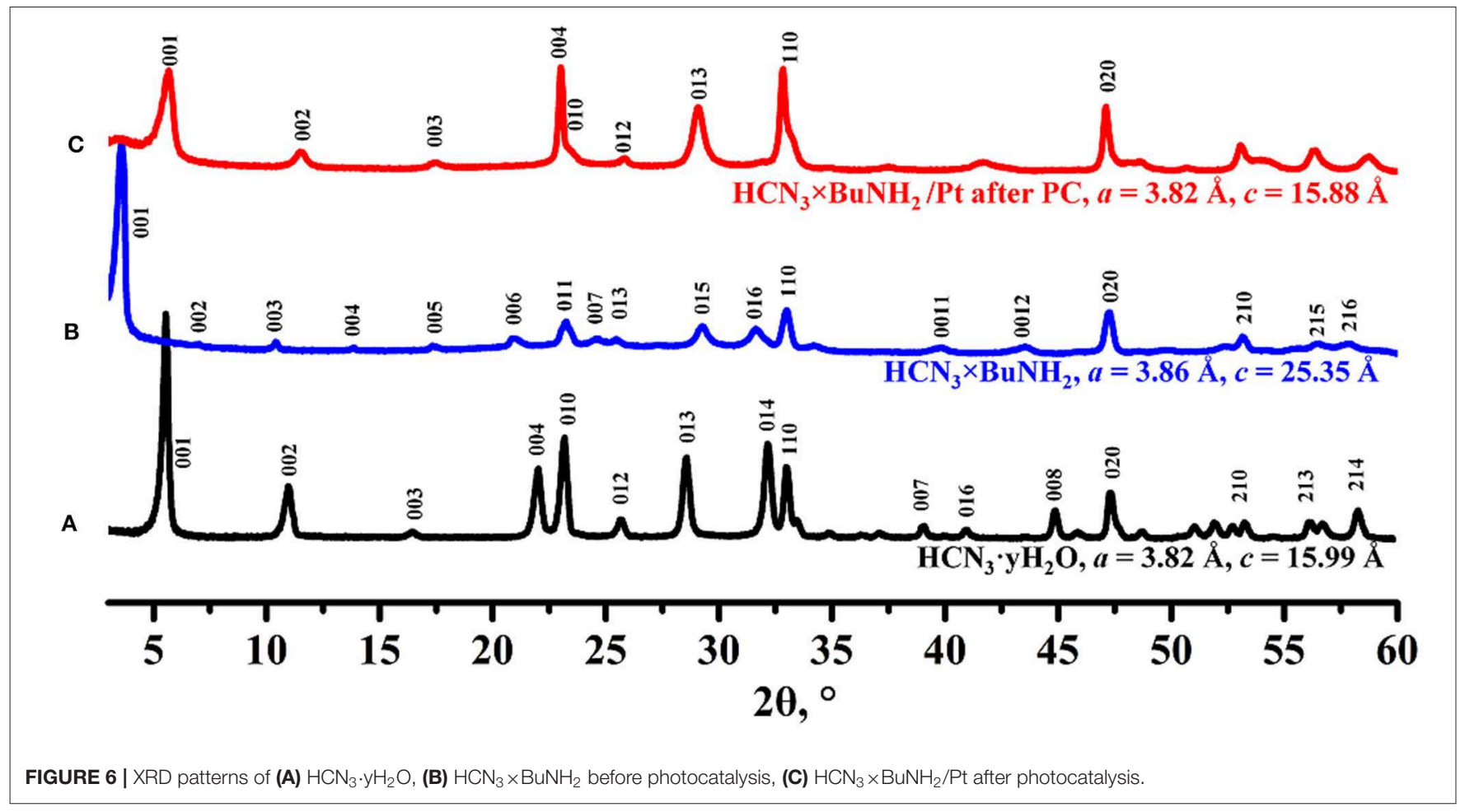

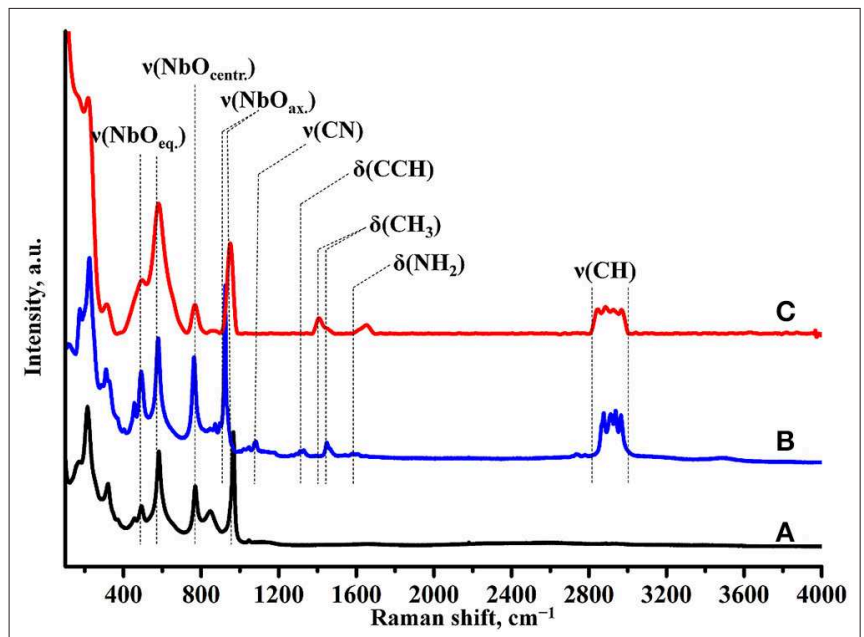

FIGURE 7 | Raman spectra of (A) $\mathrm{HCN}_{3} \cdot \mathrm{yH}_{2} \mathrm{O}$, (B) $\mathrm{HCN}_{3} \times \mathrm{BuNH}_{2}$ before photocatalysis, (C) $\mathrm{HCN}_{3} \times \mathrm{BuNH}_{2} / \mathrm{Pt}$ after photocatalysis.

activity compared to the protonated form. Subsequently, the efficiency rises with the increase of the carbon chain length of the amine reaching a maximum value of $0.22 \%$ for $\mathrm{HCN}_{3} \times \mathrm{BuNH}_{2}$. This value exceeds that for $\mathrm{HCN}_{3}$ only by a factor of 1.4. For $\mathrm{HCN}_{3} \times \mathrm{HxNH}_{2}$ and $\mathrm{HCN}_{3} \times \mathrm{OcNH}_{2}$ the hydrogen production rate decreases. Although there is no strict explanation for such behavior, we noticed, that the hydrogen evolution efficiency strongly correlates with the amount of water contained in the amine-intercalated samples

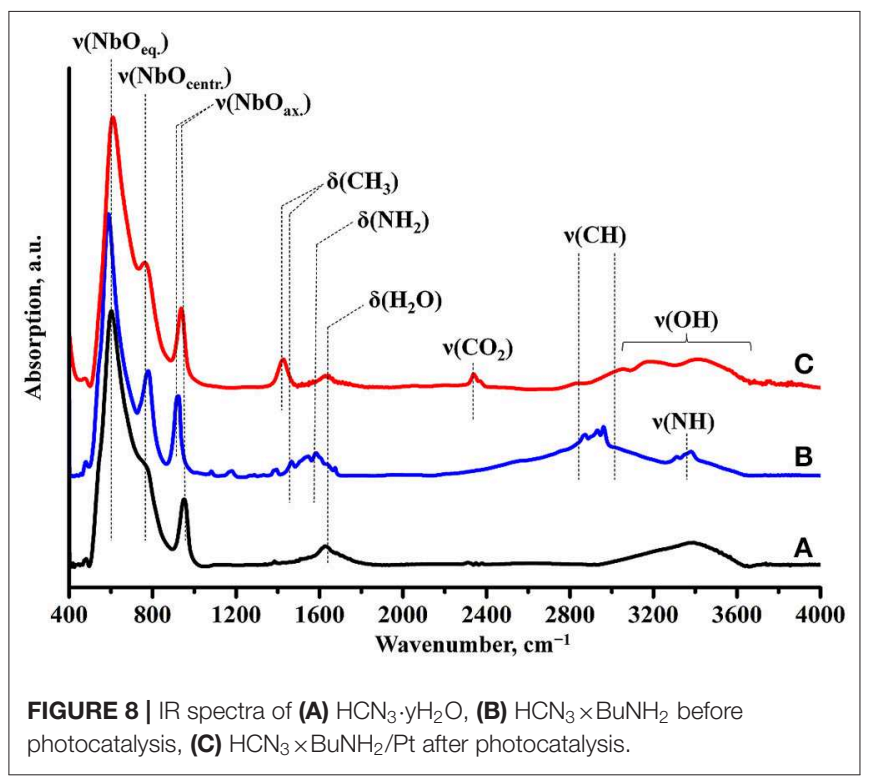

(Figure 5). Moreover, the highest photocatalytic activity was demonstrated by precisely those samples $\left(\mathrm{HCN}_{3} \times \mathrm{PrNH}_{2}\right.$ and $\mathrm{HCN}_{3} \times \mathrm{BuNH}_{2}$ ) for which the greatest tendency to hydrolysis was revealed (Supporting Information S7). We can, therefore, assume that it is the intercalated water that mainly contributes to the photocatalytic activity rather than the amine itself. The amine molecules may create transport channels for the water molecules by the expansion of the interlayer space 
and thus increase their mobility. However, in the case of compact methylamine molecules, there is almost no expansion compared with the hydrated protonated form (Figure 1). Methylamine just substitutes water in the interlayer space and thus the photocatalytic activity decreases. The results obtained are in contrast with the study of the triple-layered titanate $\mathrm{H}_{2} \mathrm{Nd}_{2} \mathrm{Ti}_{3} \mathrm{O}_{10}$ because its initial protonated form is not capable of reversible water intercalation. After loading of 1 mass. \% platinum, activities of all the samples increased 50-100 times except for the low active $\mathrm{KCN}_{3}$. The general dependence of

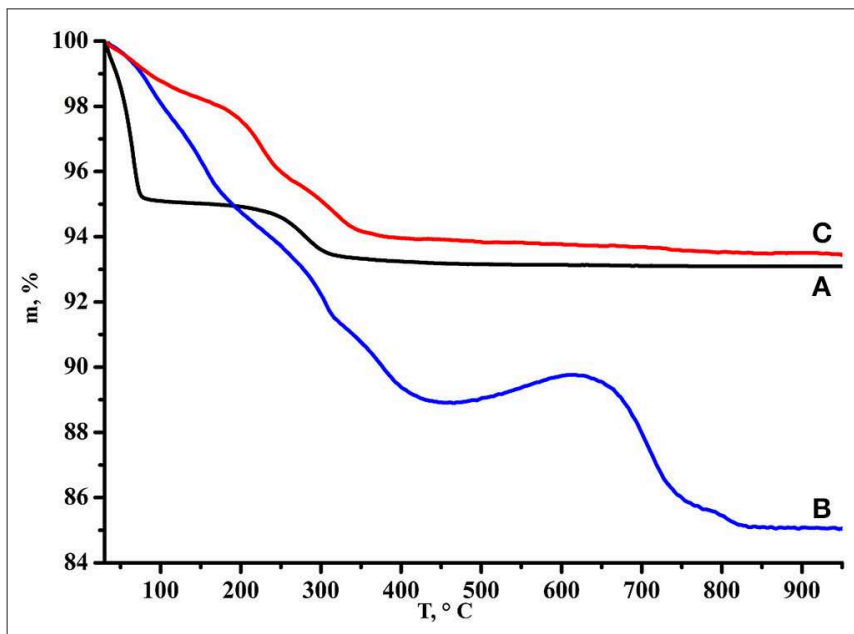

FIGURE 9 | TG curves of (A) $\mathrm{HCN}_{3} \cdot \mathrm{yH}_{2} \mathrm{O}$, (B) $\mathrm{HCN}_{3} \times \mathrm{BuNH}_{2}$ before photocatalysis, (C) $\mathrm{HCN}_{3} \times \mathrm{BuNH}_{2} / \mathrm{Pt}$ after photocatalysis. the hydrogen evolution rate on the nature of intercalated amine remains the same after platinization (Figure 5). The $\mathrm{HCN}_{3} \times \mathrm{BuNH}_{2}$ sample demonstrates the maximum quantum efficiency of $13 \%$, which is 1.6 times higher than for the protonated sample $\mathrm{HCN}_{3} \cdot \mathrm{yH}_{2} \mathrm{O}$, but 1.9 times lower than for the $n$-butylamine-intercalated $\mathrm{H}_{2} \mathrm{Nd}_{2} \mathrm{Ti}_{3} \mathrm{O}_{10}$ under the same conditions (Rodionov et al., 2019). During the photocatalytic experiment, a 14 -fold excess of hydrogen $(0.6 \mathrm{mmol})$ compared to $n$-butylamine $(0.04 \mathrm{mmol})$ was formed without significant loss of the reaction rate. Therefore, we can conclude that hydrogen is mainly formed from the reaction solution rather than from the intercalated amine. In most cases, there were no significant differences in the $\mathrm{pH}$ and suspension concentrations which could affect the results of photocatalytic experiments (Supporting Information S8).

\section{Analysis of $\mathrm{HCN}_{3} \times \mathrm{BuNH}_{2} / \mathrm{Pt}$ After the Photocatalytic Measurement}

To investigate possible changes in the structure and composition of the derivatives during the photocatalytic process, the most photocatalytically active sample $\mathrm{HCN}_{3} \times \mathrm{BuNH}_{2} / \mathrm{Pt}$ was collected after the measurement via filtering and thoroughly analyzed.

Powder XRD analysis (Figure 6) reveals that the crystal structure of the initial compound $\mathrm{HCN}_{3} \times \mathrm{BuNH}_{2}$ changed after the photocatalytic experiment. Despite the broadened reflections, the obtained compound can be indexed in the tetragonal system with lattice parameters $a=3.86 \AA, c=15.88 \AA$. This indicates a significant narrowing of the interlayer distance compared to the initial $n$-butylamine derivative $\mathrm{HCN}_{3} \times \mathrm{BuNH}_{2}$

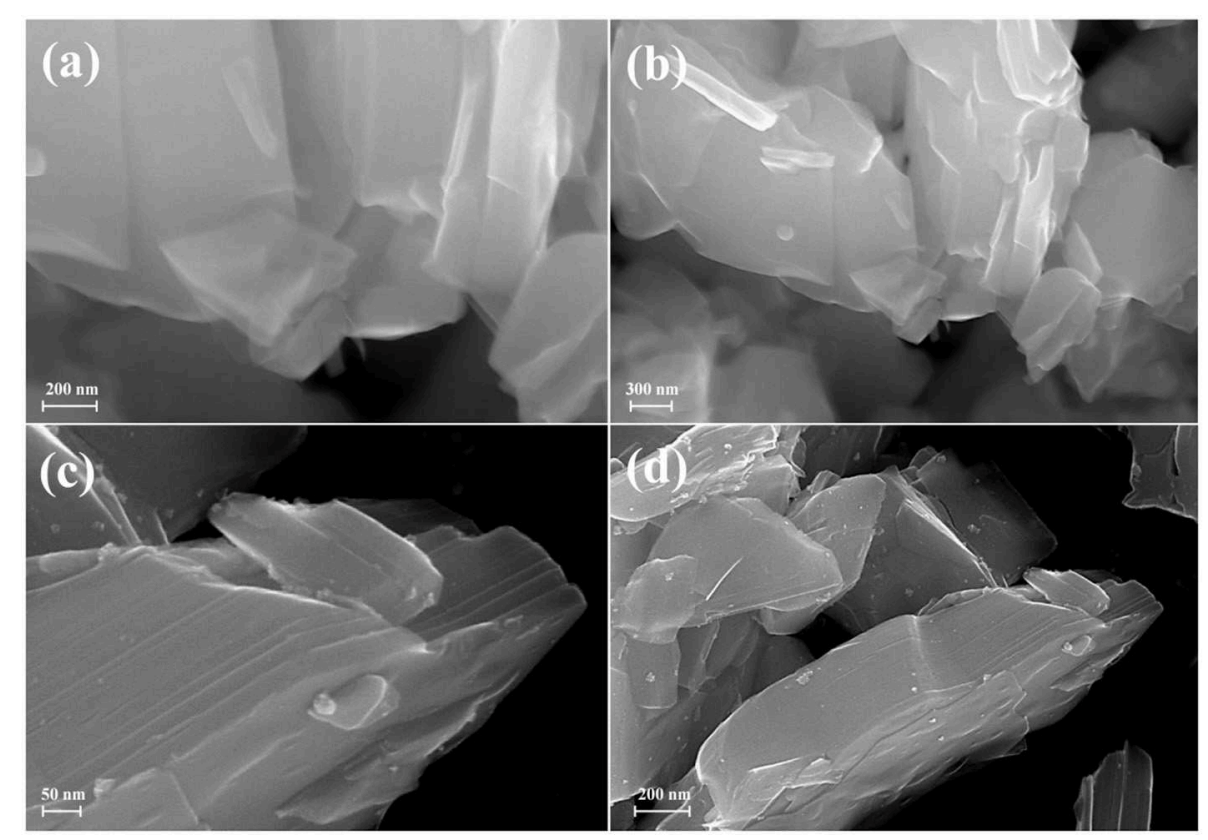

FIGURE 10 | $\mathrm{SEM}$ images of (a,b) $\mathrm{HCa}_{2} \mathrm{Nb}_{3} \mathrm{O}_{10} \times \mathrm{BuNH}_{2}$ before photocatalysis, (c,d) $\mathrm{HCa}_{2} \mathrm{Nb}_{3} \mathrm{O}_{10} \times \mathrm{BuNH}_{2} / \mathrm{Pt}_{\text {after photocatalysis. }}$ 
and is comparable to the interlayer distance of the protonated form $\mathrm{HCN}_{3} \cdot \mathrm{yH}_{2} \mathrm{O}$.

Raman spectroscopy (Figure 7) indicates the presence of the organic component in the sample after photocatalysis. However, the band, relating to latitudinal vibrations of the methyl group in the initial compound shifts from 1,445 to $1,415 \mathrm{~cm}^{-1}$, a new band at $1,650 \mathrm{~cm}^{-1}$ appears and intensity of the $\mathrm{C}-\mathrm{H}$ stretching bands $\left(2,820-3,060 \mathrm{~cm}^{-1}\right)$ decreases. These facts clearly show that the interlayer organic component inevitably undergoes some changes during the photocatalytic experiment. IR spectroscopy data (Figure 8) are fully consistent with this assumption and point at the high degree of hydration of $\mathrm{HCN}_{3} \times \mathrm{BuNH}_{2} / \mathrm{Pt}$ (wide intense band of $\mathrm{O}-\mathrm{H}$ stretching at 3,000-3,600 $\mathrm{cm}^{-1}$ ).

The TG curve of $\mathrm{HCN}_{3} \times \mathrm{BuNH}_{2} / \mathrm{Pt}$ (Figure 9) demonstrates smaller total mass loss $(6.5 \%)$ and no mass gain as compared with initial $\mathrm{HCN}_{3} \times \mathrm{BuNH}_{2}$ that points at the reduced organics fraction in the sample. Additionally, results of the $\mathrm{CHN}$ analysis $(0.77 \% \mathrm{~N}, 0.96 \% \mathrm{C}$ and $0.75 \% \mathrm{H}$ of the total sample mass) allow suggesting that organic content in the sample is low and no more than $\sim 2.5 \%$ of the total mass loss on the TG curve may be related to the organic component; the rest mass loss should correspond to the high amount of water in the sample. Moreover, the C:N ratio changes to $1.5: 1$, i.e., the carbon skeleton of the organic component does not remain unchanged.

SEM investigation (Figure 10) showed that the morphology of the sample does not considerably change during the photocatalytic measurement with platinization. Platinum nanoparticles are observed at the SEM images as light dots with linear sizes of $4-6 \mathrm{~nm}$.

\section{CONCLUSIONS}

In the presented work we have tested the photocatalytic activity of a series of $n$-alkylamine derivatives $\mathrm{HCN}_{3} \times \mathrm{RNH}_{2}(R=\mathrm{Me}$, Et, $\mathrm{Pr}, \mathrm{Bu}, \mathrm{Hx}$, and $\mathrm{Oc}$ ) of the layered niobate $\mathrm{HCa}_{2} \mathrm{Nb}_{3} \mathrm{O}_{10}$ $\left(\mathrm{HCN}_{3}\right)$. The change of the hydrogen production rate after $n$ alkylamine intercalation strongly depended on the nature of the amine. The platinized $n$-butylamine sample $\mathrm{HCN}_{3} \times \mathrm{BuNH}_{2} / \mathrm{Pt}$ showed the greatest efficiency of $\phi=13 \%$, that is 1.6 times higher compared to the initial protonated form $\mathrm{HCN}_{3} \cdot \mathrm{yH}_{2} \mathrm{O} / \mathrm{Pt}$ $(\phi=8.3 \%)$, while the methylamine sample $\mathrm{HCN}_{3} \times \mathrm{MeNH}_{2} / \mathrm{Pt}$ demonstrated the least efficiency of $\phi=2.3 \%$. The photocatalytic activity correlates with the amount of water in the interlayer space as well as the reactivity of the samples with respect to hydrolysis. Thus, we assume that it is the intercalated water that mainly contributes to the photocatalytic activity. The role of the amine may be associated with the expansion of the interlayer space that creates transport channels for water molecules and increases their mobility. On the example of the most active sample $\mathrm{HCN}_{3} \times \mathrm{BuNH}_{2}$ it was shown that the amine in the interlayer space undergoes chemical changes during the photocatalytic experiment, resulting in a decrease of the interlayer distance, a decrease of the total organic content and also a decrease of the $\mathrm{C}: \mathrm{N}$ molar ratio. However, there still remains a significant amount of organic molecules in the interlayer space that was proven by Raman spectroscopy and $\mathrm{CHN}$-analysis, and the hydrogen evolution rate remains stable during the time of the measurement. The obtained results can be used to develop relevant methods for producing hydrogen fuel using bio alcohols, the representative of which is the methanol used in the work. Despite the fact that the $n$ butylamine sample turned out to be the most active under the conditions of the experiments, a more detailed study is necessary to maximize the observed effect of intercalation of organic amines, which includes variation of experimental conditions and testing of a wider range of introduced compounds. Also, further studies will be performed to investigate carefully the composition, structure and properties of the samples obtained after photocatalytic measurements.

\section{DATA AVAILABILITY STATEMENT}

The datasets generated for this study are available on request to the corresponding author.

\section{AUTHOR CONTRIBUTIONS}

IR, OS, and IZ contributed conception and design of the study. Experimental work was carried out by VV and SK (photocatalytic experiments), VV, SK, and IM (synthesis, characterization) under supervision of IR, OS, and IZ. All authors participated in the analysis and discussion of the obtained results. SK and OS wrote the manuscript and prepared images with contributions of IR and VV in certain sections.

\section{FUNDING}

This study was financially supported by the Russian Science Foundation (project No 19-13-00184).

\section{ACKNOWLEDGMENTS}

The study was technically supported by the Saint Petersburg State University Research Park. Authors are grateful to the Centre for X-ray Diffraction Studies (XRD analysis), Centre for Optical and Laser Materials Research (Raman spectroscopy), Centre for Chemical Analysis and Materials Research (IR spectroscopy, DRS, CHN analysis), Centre for Thermal Analysis and Calorimetry (TG analysis), Interdisciplinary Centre for Nanotechnology (SEM), Centre for Innovative Technologies of Composite Nanomaterials (BET).

\section{SUPPLEMENTARY MATERIAL}

The Supplementary Material for this article can be found online at: https://www.frontiersin.org/articles/10.3389/fchem. 2020.00300/full\#supplementary-material 


\section{REFERENCES}

Boykin, J. R., and Smith, L. J. (2015). Rapid microwave-assisted grafting of layered perovskites with $\mathrm{n}$-alcohols. Inorg. Chem. 54, 4177-4179. doi: $10.1021 /$ ic $503001 \mathrm{w}$

Chen, W., Li, C., Gao, H., Yuan, J., Shangguan, W., Su, J., et al. (2012). Photocatalytic water splitting on protonated form of layered perovskites $\mathrm{K}_{0.5} \mathrm{La}_{0.5} \mathrm{Bi}_{2} \mathrm{M}_{2} \mathrm{O}_{9}(\mathrm{M}=\mathrm{Ta} ; \mathrm{Nb})$ by ion-exchange. Int. J. Hydrogen Energy 37, 12846-12851. doi: 10.1016/j.ijhydene.2012.05.090

Compton, O. C., Carroll, E. C., Kim, J. Y., Larsen, D. S., and Osterloh, F. E. (2007). Calcium niobate semiconductor nanosheets as catalysts for photochemical hydrogen evolution from water. J. Phys. Chem. C 111, 14589-14592. doi: 10.1021/jp0751155

Cui, W., Guo, D., Liu, L., Hu, J., Rana, D., and Liang, Y. (2014). Preparation of $\mathrm{ZnIn}_{2} \mathrm{~S}_{4} / \mathrm{K}_{2} \mathrm{La}_{2} \mathrm{Ti}_{3} \mathrm{O}_{10}$ composites and their photocatalytic $\mathrm{H}_{2}$ evolution from aqueous $\mathrm{Na}_{2} \mathrm{~S}_{2} \mathrm{Na}_{2} \mathrm{SO}_{3}$ under visible light irradiation. Catal. Commun. 48, 55-59. doi: 10.1016/j.catcom.2014.01.026

Cui, W., Liu, L., Ma, S., Liang, Y., and Zhang, Z. (2013). CdSsensitized $\mathrm{K}_{2} \mathrm{La}_{2} \mathrm{Ti}_{3} \mathrm{O}_{10}$ composite: a new photocatalyst for hydrogen evolution under visible light irradiation. Catal. Today 207, 44-49. doi: 10.1016/j.cattod.2012.05.009

Cui, W., Qi, Y., Liu, L., Rana, D., Hu, J., and Liang, Y. (2012). Synthesis of $\mathrm{PbS}-\mathrm{K}_{2} \mathrm{La}_{2} \mathrm{Ti}_{3} \mathrm{O}_{10}$ composite and its photocatalytic activity for hydrogen production. Prog. Nat. Sci. Mater. Int. 22, 120-125. doi: $10.1016 /$ j.pnsc.2012.03.002

Dion, M., Ganne, M., and Tournoux, M. (1981). Nouvelles familles de phases $\mathrm{M}^{\mathrm{I}} \mathrm{M}_{2}^{\mathrm{II}} \mathrm{Nb}_{3} \mathrm{O}_{10}$ a feuillets "perovskites." Mater. Res. Bull. 16, 1429-1435. doi: 10.1016/0025-5408(81)90063-5

Domen, K., Yoshimura, J., Sekine, T., Kondo, J., Tanaka, A., Maruya, K., et al. (1993). A novel series of photocatalysts with an ionexchangeable layered structure of niobate. Stud. Surf. Sci. Catal. 2159-2162. doi: 10.1016/S0167-2991(08)64250-0

Ebina, Y., Sasaki, T., and Watanabe, M. (2002). Study on exfoliation of layered perovskite-type niobates. Solid State Ionics 151, 177-182. doi: 10.1016/S0167-2738(02)00707-5

Fukuoka, H., Isami, T., and Yamanaka, S. (2000). Crystal structure of a layered perovskite niobate $\mathrm{KCa}_{2} \mathrm{Nb}_{3} \mathrm{O}_{10}$. J. Solid State Chem. 151, 40-45. doi: $10.1006 /$ jssc.2000.8619

Guo, T., Wang, L., Evans, D. G., and Yang, W. (2010). Synthesis and photocatalytic properties of a polyaniline-intercalated layered protonic titanate nanocomposite with a $\mathrm{p}-\mathrm{n}$ heterojunction structure. J. Phys. Chem. C 114, 4765-4772. doi: 10.1021/jp9055413

Han, Y.-S., Park, I., and Choy, J.-H. (2001). Exfoliation of layered perovskite, $\mathrm{KCa}_{2} \mathrm{Nb}_{3} \mathrm{O}_{10}$, into colloidal nanosheets by a novel chemical process. J. Mater. Chem. 11, 1277-1282. doi: 10.1039/b006045n

Hong, Y., and Kim, S.-J. (1996). Intercalation of primary diamines in the layered perovskite oxides, $\mathrm{HSr}_{2} \mathrm{Nb}_{3} \mathrm{O}_{10}$. Bull. Korean Chem. Soc. 17, 730-735.

Huang, Y., Li, J., Wei, Y., Li, Y., Lin, J., and Wu, J. (2009). Fabrication and photocatalytic property of Pt-intercalated layered perovskite niobates $\mathrm{H}_{1-\mathrm{x}} \mathrm{LaNb}_{2-\mathrm{x}} \mathrm{Mo}_{\mathrm{x}} \mathrm{O}_{7} \quad(x=0-0.15)$. J. Hazard. Mater. 166, 103-108. doi: 10.1016/j.jhazmat.2008.11.040

Huang, Y., Li, Y., Wei, Y., Huang, M., and Wu, J. (2011). Photocatalytic property of partially substituted Pt-intercalated layered perovskite, $\mathrm{ASr}_{2} \mathrm{Ta}_{\mathrm{x}} \mathrm{Nb}_{3-\mathrm{x}} \mathrm{O}_{10}$ $(\mathrm{A}=\mathrm{K}, \mathrm{H} ; \mathrm{x}=0,1,1.5,2$ and 3). Sol. Energy Mater. Sol. Cells 95, 1019-1027. doi: 10.1016/j.solmat.2010.12.017

Huang, Y., Wu, J., Li, T., Hao, S., and Lin, J. (2006). Synthesis and photocatalytic properties of $\mathrm{H}_{2} \mathrm{La}_{2} \mathrm{Ti}_{3} \mathrm{O}_{10} / \mathrm{TiO}_{2}$ intercalated nanomaterial. J. Porous Mater. 13, 55-59. doi: 10.1007/s10934-006-5490-6

Jacobson, A. J., Johnson, J. W., and Lewandowski, J. (1987). Intercalation of the layered solid acid $\mathrm{HCa}_{2} \mathrm{Nb}_{3} \mathrm{O}_{10}$ by organic amines. Mater. Res. Bull. 22, 45-51. doi: 10.1016/0025-5408(87)90148-6

Jacobson, A. J., Johnson, J. W., and Lewandowski, J. T. (1985). Interlayer chemistry between thick transition-metal oxide layers: synthesis and intercalation

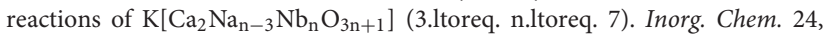
3727-3729. doi: 10.1021/ic00217a006

Jacobson, A. J., Lewandowski, J. T., and Johnson, J. W. (1986). Ion exchange of the layered perovskite $\mathrm{KCa}_{2} \mathrm{Nb}_{3} \mathrm{O}_{10}$ by protons. J. Less Common Met. 116, 137-146. doi: 10.1016/0022-5088(86)90224-9
Kawashima, K., Hojamberdiev, M., Chen, S., Yubuta, K., Wagata, H., Domen, $\mathrm{K}$., et al. (2017). Understanding the effect of partial $\mathrm{N}^{3-}$ to $\mathrm{O}^{2-}$ substitution and $\mathrm{H}^{+}$to $\mathrm{K}^{+}$exchange on photocatalytic water reduction activity of Ruddlesden-Popper layered perovskite $\mathrm{KLaTiO}_{4}$. Mol. Catal. 432, 250-258. doi: 10.1016/j.mcat.2017.01.004

Kickelbick, G. (2007). Hybrid Materials: Synthesis, Characterization, and Applications. Weinheim: Wiley-VCH Verlag GmbH \& Co. KGaA.

Kumar, V., Govind., and Uma, S. (2011). Investigation of cation $\left(\mathrm{Sn}^{2+}\right)$ and anion $\left(\mathrm{N}^{3-}\right)$ substitution in favor of visible light photocatalytic activity in the layered perovskite $\mathrm{K}_{2} \mathrm{La}_{2} \mathrm{Ti}_{3} \mathrm{O}_{10}$. J. Hazard. Mater. 189, 502-508. doi: 10.1016/j.jhazmat.2011.02.064

Kurnosenko, S. A., Silyukov, O. I., Mazur, A. S., and Zvereva, I. A. (2019). Synthesis and thermal stability of new inorganic-organic perovskite-like hybrids based on layered titanates $\mathrm{HLnTiO}_{4}(\mathrm{Ln}=\mathrm{La}, \mathrm{Nd})$. Ceram. Int. 46, 5058-5068. doi: 10.1016/j.ceramint.2019.10.249

Liu, C., Wu, L., Chen, J., Liang, J. Y., Li, C. S., Ji, H. M., et al. (2014). The nanocomposite of polyaniline and nitrogen-doped layered $\mathrm{HTiNbO}_{5}$ with excellent visible-light photocatalytic performance. Phys. Chem. Chem. Phys. 16, 13409-13417. doi: 10.1039/c4cp01423e

Liu, Y., Zhou, Y., Lv, C., Zhang, C., Jin, X., Meng, Q., et al. (2018). Construction of 2D-composite $\mathrm{HCa}_{2} \mathrm{Nb}_{3} \mathrm{O}_{10} / \mathrm{CaNb}_{2} \mathrm{O}_{6}$ heterostructured photocatalysts with enhanced hydrogen production performance. New J. Chem. 42, 681-687. doi: $10.1039 / \mathrm{C} 7 \mathrm{NJ} 03707 \mathrm{D}$

Machida, M., Mitsuyama, T., Ikeue, K., Matsushima, S., and Arai, M. (2005). Photocatalytic property and electronic structure of triple-layered perovskite tantalates, $\mathrm{MCa}_{2} \mathrm{Ta}_{3} \mathrm{O}_{10}\left(\mathrm{M}=\mathrm{Cs}, \mathrm{Na}, \mathrm{H}\right.$, and $\left.\mathrm{C}_{6} \mathrm{H}_{13} \mathrm{NH}_{3}\right)$. J. Phys. Chem. $B$ 109, 7801-7806. doi: 10.1021/jp044833d

Maeda, K. (2011). Photocatalytic water splitting using semiconductor particles: history and recent developments. J. Photochem. Photobiol. C Photochem. Rev. 12, 237-268. doi: 10.1016/j.jphotochemrev.2011.07.001

Mir, S. H., Nagahara, L. A., Thundat, T., Mokarian-Tabari, P., Furukawa, H., and Khosla, A. (2018). Review-organic-inorganic hybrid functional materials: an integrated platform for applied technologies. J. Electrochem. Soc. 165, B3137B3156. doi: 10.1149/2.0191808jes

Oshima, T., Ishitani, O., and Maeda, K. (2014). Non-sacrificial water photooxidation activity of lamellar calcium niobate induced by exfoliation. $A d v$. Mater. Interfaces 1:1400131. doi: 10.1002/admi.201400131

Reddy, V., Hwang, D., and Lee, J. (2003). Effect of $\mathrm{Zr}$ substitution for $\mathrm{Ti}$ in $\mathrm{KLaTiO}_{4}$ for photocatalytic water splitting. Catal. Lett. 90, 39-44. doi: 10.1023/A:1025812125852

Rodionov, I., Maksimova, E., Pozhidaev, A., Kurnosenko, S., Silyukov, O., and Zvereva, I. (2019). Layered Titanate $\mathrm{H}_{2} \mathrm{Nd}_{2} \mathrm{Ti}_{3} \mathrm{O}_{10}$ intercalated with n-Butylamine: a new highly efficient hybrid photocatalyst for hydrogen production from Aqueous solutions of Alcohols. Front. Chem. 7:863. doi: 10.3389/fchem.2019.00863

Rodionov, I. A., Mechtaeva, E. V., Burovikhina, A. A., Silyukov, O. I., Toikka, M. A., and Zvereva, I. A. (2018). Effect of protonation on the photocatalytic activity of the $\mathrm{K}_{2} \mathrm{La}_{2} \mathrm{Ti}_{3} \mathrm{O}_{10}$ layered oxide in the reaction of hydrogen production. Chem. Mon. 149, 475-482. doi: 10.1007/s00706-017-2105-7

Rodionov, I. A., Silyukov, O. I., Utkina, T. D., Chislov, M. V., Sokolova, Y. P., and Zvereva, I. A. (2012). Photocatalytic properties and hydration of perovskitetype layered titanates $\mathrm{A}_{2} \mathrm{Ln}_{2} \mathrm{Ti}_{3} \mathrm{O}_{10}(\mathrm{~A}=\mathrm{Li}, \mathrm{Na}, \mathrm{K} ; \mathrm{Ln}=\mathrm{La}, \mathrm{Nd})$. Russ. J. Gen. Chem. 82, 1191-1196. doi: 10.1134/S1070363212070018

Rodionov, I. A., Sokolova, I. P., Silyukov, O. I., Burovikhina, A. A., Fateev, S. A., and Zvereva, I. A. (2017). Protonation and photocatalytic activity of the $\mathrm{Rb}_{2} \mathrm{La}_{2} \mathrm{Ti}_{3} \mathrm{O}_{10}$ layered oxide in the reaction of hydrogen production. Int. J. Photoenergy 2017:9628146. doi: 10.1155/2017/ 9628146

Sabio, E. M., Chamousis, R. L., Browning, N. D., and Osterloh, F. E. (2012). Photocatalytic water splitting with suspended calcium Niobium oxides: why nanoscale is better than bulk-a kinetic analysis. J. Phys. Chem. C 116, 3161-3170. doi: 10.1021/jp209006n

Saito, K., Kozeni, M., Sohmiya, M., Komaguchi, K., Ogawa, M., Sugahara, Y., et al. (2016). Unprecedentedly enhanced solar photocatalytic activity of a layered titanate simply integrated with $\mathrm{TiO}_{2}$ nanoparticles. Phys. Chem. Chem. Phys. 18, 30920-30925. doi: 10.1039/c6cp05635k

Sanchez, P. G.-R. C. (2006). Functional Hybrid Materials. Weinheim: Wiley-VCH Verlag GmbH \& Co. KGaA. 
Sato, S., Shintani, K., Idota, N., Nishino, T., and Sugahara, Y. (2017). Effect of the graft density of cellulose diacetate-modified layered perovskite nanosheets on mechanical properties of the transparent organic-inorganic hybrids bearing covalent bonds at the interface. Cellulose 24, 5463-5473. doi: 10.1007/s10570-017-1475-7

Schaak, R. E., and Mallouk, T. E. (2000). Prying apart ruddlesden-popper phases: exfoliation into sheets and nanotubes for assembly of perovskite thin films. Chem. Mater. 12, 3427-3434. doi: 10.1021/cm000495r

Seiichi, T., and Tahara, S. (2007). Preparation of Inorganic-Organic Hybrids via Intercalation and Grafting Reactions of Protonated Forms of Ion-Exchangeable Layered Perovskites Thesis Submitted To Waseda University Seiichi Tahara. Available online at: https://dspace.wul.waseda.ac.jp/dspace/handle/2065/28481 (accessed December 23, 2012).

Shelyapina, M. G., Nefedov, D. Y., Kostromin, A. V., Silyukov, O. I., and Zvereva, I. A. (2019). Proton mobility in Ruddlesden-Popper phase $\mathrm{H}_{2} \mathrm{La}_{2} \mathrm{Ti}_{3} \mathrm{O}_{10}$ studied by 1 H NMR. Ceram. Int. 45, 5788-5795. doi: 10.1016/j.ceramint.2018.12.045

Shimizu, K., Itoh, S., Hatamachi, T., Kitayama, Y., and Kodama, T. (2006). Pillaring of Ruddlesden-Popper perovskite tantalates, $\mathrm{H}_{2} \mathrm{ATa}_{2} \mathrm{O}_{7}\left(\mathrm{~A}=\mathrm{Sr}\right.$ or $\left.\mathrm{La}_{2 / 3}\right)$, with n-alkylamines and oxide nanoparticles. J. Mater. Chem. 16, 773-779. doi: 10.1039/b514066h

Shori, S., Pellechia, P. J., Zur Loye, H.-C., and Ploehn, H. J. (2015). Covalent grafting of phenylphosphonate on calcium niobate platelets. J. Colloid Interface Sci. 437, 97-110. doi: 10.1016/j.jcis.2014.09.024

Silyukov, O. I., Abdulaeva, L. D., Burovikhina, A. A., Rodionov, I. A., and Zvereva, I. A. (2015). Phase transformations during $\mathrm{HLnTiO}_{4}(\mathrm{Ln}=\mathrm{La}, \mathrm{Nd})$ thermolysis and photocatalytic activity of obtained compounds. J. Solid State Chem. 226, 101-106. doi: 10.1016/j.jssc.2015.02.008

Silyukov, O. I., Kurnosenko, S. A., and Zvereva, I. A. (2018). Intercalation of Methylamine into the protonated forms of layered Perovskite-like oxides $\mathrm{HLnTiO}_{4}$ ( $\mathrm{Ln}=\mathrm{La}$ and Nd). Glas. Phys. Chem. 44, 428-432. doi: 10.1134/S1087659618050176

Tahara, S., Ichikawa, T., Kajiwara, G., and Sugahara, Y. (2007). Reactivity of the Ruddlesden-Popper phase $\mathrm{H}_{2} \mathrm{La}_{2} \mathrm{Ti}_{3} \mathrm{O}_{10}$ with organic compounds: intercalation and grafting reactions. Chem. Mater. 19, 2352-2358. doi: $10.1021 / \mathrm{cm} 0623662$

Tahara, S., and Sugahara, Y. (2003). Interlayer surface modification of the protonated triple-layered perovskite $\mathrm{HCa}_{2} \mathrm{Nb}_{3} \mathrm{O}_{10} \cdot \mathrm{xH}_{2} \mathrm{O}$ with $\mathrm{n}$-Alcohols. Langmuir 19, 9473-9478. doi: 10.1021/la0343876

Takahashi, S., Nakato, T., Hayashi, S., Sugahara, Y., and Kuroda, K. (1995). Formation of Methoxy-modified interlayer surface via the reaction between methanol and layered perovskite HLaNb2O7.cntdot.xH2O. Inorg. Chem. 34, 5065-5069. doi: 10.1021/ic00124a023

Takeda, Y., Momma, T., Osaka, T., Kuroda, K., and Sugahara, Y. (2008). Organic derivatives of the layered perovskite $\mathrm{HLaNb}_{2} \mathrm{O}_{7} \cdot \mathrm{xH}_{2} \mathrm{O}$ with polyether chains on the interlayer surface: characterization, intercalation of $\mathrm{LiClO}_{4}$, and ionic conductivity. J. Mater. Chem. 18, 3581-3587. doi: 10.1039/b802003e

Takeda, Y., Suzuki, H., Notsu, K., Sugimoto, W., and Sugahara, Y. (2006). Preparation of a novel organic derivative of the layered perovskite bearing $\mathrm{HLaNb}_{2} \mathrm{O}_{7} \cdot \mathrm{nH}_{2} \mathrm{O}$ interlayer surface trifluoroacetate groups. Mater. Res. Bull. 41, 834-841. doi: 10.1016/j.materresbull.2005.10.004

Tong, Z., Zhang, G., Takagi, S., Shimada, T., Tachibana, H., and Inoue, H. (2005). Preparation and characterization of a transparent thin film of the layered perovskite, $\mathrm{K}_{2} \mathrm{La}_{2} \mathrm{Ti}_{3} \mathrm{O}_{10}$, intercalated with an ionic porphyrin. Chem. Lett. 34, 632-633. doi: 10.1246/cl.2005.632

Tsunoda, Y., Sugimoto, W., and Sugahara, Y. (2003). Intercalation behavior of $\mathrm{n}$-alkylamines into a protonated form of a layered perovskite derived from aurivillius phase $\mathrm{Bi}_{2} \mathrm{SrTa}_{2} \mathrm{O}_{9}$. Chem. Mater. 15, 632-635. doi: $10.1021 / \mathrm{cm} 0200893$
Uma, S., and Gopalakrishnan, J. (1994). Synthesis of anion-deficient layered perovskites, $\mathrm{ACa}_{2} \mathrm{Nb}_{3-\mathrm{x}} \mathrm{M}_{\mathrm{x}} \mathrm{O}_{10-\mathrm{x}}(\mathrm{A}=\mathrm{Rb}, \mathrm{Cs} ; \mathrm{M}=\mathrm{Al}, \mathrm{Fe})$, exhibiting ion-exchange and intercalation. evidence for the formation of layered brownmillerites, $\mathrm{ACa}_{2} \mathrm{Nb}_{2} \mathrm{AlO}_{9}(\mathrm{~A}=\mathrm{Cs}, \mathrm{H})$. Chem. Mater. 6, 907-912. doi: $10.1021 / \mathrm{cm} 00043 \mathrm{a} 008$

Uma, S., Gopalakrishnan, J., State, S., and Unit, S. C. (1995). Polymerization of aniline in layered perovskites. Mater. Sci. 34, 175-179. doi: 10.1016/0921-5107(95)01235-4

Wang, B., Dong, X., Pan, Q., Cheng, Z., and Yang, Y. (2007). Intercalation behavior of $\mathrm{n}$-alkylamines into an A-site defective layered perovskite $\mathrm{H}_{2} \mathrm{~W}_{2} \mathrm{O}_{7}$. J. Solid State Chem. 180, 1125-1129. doi: 10.1016/j.jssc.2007. 01.009

Wang, C., Tang, K., Wang, D., Liu, Z., Wang, L., Zhu, Y., et al. (2012). A new carbon intercalated compound of Dion-Jacobson phase $\mathrm{HLaNb}_{2} \mathrm{O}_{7}$. J. Mater. Chem. 22, 11086-11092. doi: 10.1039/c2jm $14902 \mathrm{~h}$

Wang, Y., Nikolopoulou, M., Delahaye, E., Leuvrey, C., Leroux, F., Rabu, P., et al. (2018). Microwave-assisted functionalization of the Aurivillius phase $\mathrm{Bi}_{2} \mathrm{SrTa}_{2} \mathrm{O}_{9}$ : diol grafting and amine insertion vs. alcohol grafting. Chem. Sci. 9, 7104-7114. doi: 10.1039/C8SC01754A

Wang, Y., Wang, C., Wang, L., Hao, Q., Zhu, X., Chen, X., et al. (2014). Preparation of interlayer surface tailored protonated double-layered perovskite $\mathrm{H}_{2} \mathrm{CaTa}_{2} \mathrm{O}_{7}$ with n-alcohols, and their photocatalytic activity. RSC Adv. 4, 4047-4054. doi: 10.1039/C3RA44623A

Youngblood, W. J., Lee, S.-H. A., Maeda, K., and Mallouk, T. E. (2009). Visible light water splitting using dye-sensitized oxide semiconductors. Acc. Chem. Res. 42, 1966-1973. doi: 10.1021/ar9002398

Zhou, Y., Wen, T., Guo, Y., Yang, B., and Wang, Y. (2016). Controllable doping of nitrogen and tetravalent niobium affords yellow and black calcium niobate nanosheets for enhanced photocatalytic hydrogen evolution. RSC Adv. 6, 64930-64936. doi: 10.1039/C6RA11407E

Zhu, H., Yao, X., and Hua, S. (2013). Nanocomposite of polyaniline and a layered niobate acid host: synthesis, electrochemical studies, and photocatalytic properties. Polym. Compos. 34, 834-841. doi: 10.1002/pc.22485

Zou, Z., Ye, J., and Arakawa, H. (2001). Substitution effects of $\mathrm{In}^{3+}$ by $\mathrm{Fe}^{3+}$ on photocatalytic and structural properties of $\mathrm{Bi}_{2} \mathrm{InNbO}_{7}$ photocatalysts. J. Mol. Catal. 168, 289-297. doi: 10.1016/S1381-1169(00)00545-8

Zvereva, I., and Rodionov, I. (2013). "Photocatalytic properties of perovskitetype layered oxides," in Perovskite: Crystallography, Chemistry and Catalytic Performance, eds J. Zhang and H. Li (New York, NY: Nova Science Publishers), 181-198. Available online at: https://www.novapublishers.com/ catalog/product_info.php?products_id=35898

Zvereva, I. A., Silyukov, O. I., and Chislov, M. V. (2011). Ion-exchange reactions in the structure of perovskite-like layered oxides: I. Protonation of $\mathrm{NaNdTiO}_{4}$ complex oxide. Russ. J. Gen. Chem. 81, 1434-1441. doi: 10.1134/S1070363211070061

Conflict of Interest: The authors declare that the research was conducted in the absence of any commercial or financial relationships that could be construed as a potential conflict of interest.

Copyright (C) 2020 Voytovich, Kurnosenko, Silyukov, Rodionov, Minich and Zvereva. This is an open-access article distributed under the terms of the Creative Commons Attribution License (CC BY). The use, distribution or reproduction in other forums is permitted, provided the original author(s) and the copyright owner(s) are credited and that the original publication in this journal is cited, in accordance with accepted academic practice. No use, distribution or reproduction is permitted which does not comply with these terms. 